\title{
DECISÕES E AÇÕES ASSOCIADAS AO EMPREENDEDORISMO E À INOVAÇÃO: O DESAFIO DA SCHULER CALÇADOS
}

\author{
DECISIONS AND ACTIONS RELATED TO ENTREPRENEURSHIP \\ AND INNOVATION: THE SCHULER FOOTWEAR CHALLENGE
}

Recebido em: 03/02/2012 Aprovado em: 10/04/2012 Avaliado pelo sistema double blind review Editora Científica: Manolita Correia Lima

\section{ELIANAANDRÉA SEVERO elianasevero2@hotmail.com MARCIA RHOR DA CRUZ \\ PELAYO MUNHOZ OLEA \\ ERIC DORION \\ JULIO CESAR FERRO DE GUIMARÃES UNIVERSIDADE DE CAXIAS DO SUL}

\section{RESUMO}

O arranjo produtivo do Vale do Rio dos Sinos, situado no Rio Grande do Sul, no ano de 1993 possuía cerca de I950 empresas calçadistas, gerava 29 mil empregos diretos e exportava em torno de 201 milhões de pares de calçados. No entanto, a partir do ano 1994 ocorreram importantes mudanças no ambiente competitivo do qual participavam as empresas calçadistas brasileiras. As indústrias calçadistas do Vale do Rio dos Sinos sentiram de forma diferenciada os impactos do novo ambiente competitivo, e passaram a adotar novas estratégias tecnológicas e de reestruturação. O principal objetivo era a redução dos custos de produção, para manter a competitividade no preço do produto. O objetivo desse caso de ensino é propor reflexões sobre as decisões e ações associadas ao empreendedorismo e à inovação no contexto da Indústria Calçadista. Esse caso procura fazer uma discussão, levantando e sugerindo o impacto que surge com base nas decisões estratégicas e nas mudanças mercadológicas no cenário globalizado e cada vez mais competitivo. Sua utilização está indicada em cursos de graduação em administração, nas disciplinas de teorias organizacionais, diretrizes e planejamento empresarial, administração de novos negócios, estratégia de inserção internacional e inteligência competitiva.

Palavras-chave: setor calçadista; empreendedorismo; inovação

\section{ABSTRACT}

In 1993, the Valley do Rio dos Sinos manufacturing park located in Rio Grande do Sul had about 1,950 footwear companies accounting for approximately 129,000 jobs and responsible for exporting around 201 million pairs of shoes. However, from 1994, significant changes took place in the competitive environment of these Brazilian footwear companies. The Valley do Rio dos Sinos footwear industries felt the impacts of this new competitive environment in different ways and subsequently adopted new technological and restructuring strategies. The main objective was to reduce production costs in order to remain competitive in price. The aim of this case study is to propose thoughts on the decisions and actions associated with entrepreneurship and innovation in the context of the footwear industry. This case seeks to raise a discussion and suggest the impact that arises from the strategic decisions made and to understand these increasingly competitive changing markets in a global scenario. It is recommended for use in undergraduate business administration courses, for the disciplines of organizational theories, business planning and guidelines, new business administration, international insertion strategy and competitive intelligence.

Keywords: footwear industry; entrepreneurship; innovation. 


\section{INTRODUÇÃO}

A origem calçadista da região do Vale do Rio dos Sinos, situado no Rio Grande do Sul, remonta a I824, com a vinda dos primeiros imigrantes alemães, que iniciaram a produção de arreios e botinas de couro. As atividades associadas com a produção de calçados evoluíram rapidamente na região Sul, principalmente na localidade que, mais tarde, se tornou o município de Novo Hamburgo, tendo em vista a existência de vários estabelecimentos fabricantes de arreios, que originavam muitas aparas de couro, que passaram a ser utilizadas na fabricação caseira de chinelos, comercializados na localidade.

De 1930 a 1950, a indústria calçadista estendeu-se por todas as cidades do Vale dos Sinos. A expressão Vale dos Sinos é utilizada para referir um conjunto de municípios que se localizam em torno do rio que lhe dá o nome (Rio dos Sinos). A utilização dessa expressão vinculada à produção de calçados tem a intenção de identificar aquelas empresas associadas a essa atividade e que estejam localizadas em municípios próximos a esse rio ou afluentes. Entre os municípios que se destacam como produtores de calçados, podem ser citadas as cidades de Campo Bom, Dois Irmãos, Estância Velha, Gramado, Igrejinha, Ivoti, Nova Hartz, Nova Petrópolis, Novo Hamburgo, Parobé, Picada Café, Portão, Riozinho, Rolante, Santo Antônio da Patrulha, São Francisco de Paula, São Leopoldo, Sapiranga, Taquara e Três Coroas (fensterseifer; gOMes, 1995). Todas estas cidades estão localizadas no estado do Rio Grande do Sul.

A partir do final da década de 1960, o setor calçadista começou a atuar com força no comércio exterior. Entre 1973 e 1984 ocorreu uma explosão de exportações, de 773 milhões de dólares em 1984. Na década de 1980, o Vale do Rio dos Sinos era considerado um grande cluster do calçado. A grande concentração de empresas especializadas em calçados de couro femininos formava um dos maiores arranjos produtivos do setor, no mundo.

A indústria calçadista gaúcha caminhou na contramão da história do país, pois quando este se abatia em anos de crise, aquela indústria crescia a largos passos. Entre 1970 e 1990, o Brasil aumentou sua participação nas 
exportações mundiais de calçados de $0,5 \%$ para $\mathrm{I} 2,3 \%$, e o país tornou-se o terceiro maior exportador de calçados do mundo.

O arranjo produtivo do Vale do Rio dos Sinos no ano de 1993 possuía cerca de 1950 empresas calçadistas, gerava 129 mil empregos diretos. Em torno de 201 milhões de pares de calçados foram exportados.

No entanto, a partir do ano 1994 ocorreram importantes mudanças no ambiente competitivo, da qual participavam as empresas calçadistas brasileiras. A economia mundial passou por várias transformações. As flutuações cambiais também influenciaram a competitividade brasileira no complexo calçadista. Neste contexto, a partir de I994, com a implantação do Plano Real, as exportações passaram por dificuldades, decorrentes da sobrevalorização cambial, enquanto, em I999, a desvalorização da moeda refletiu-se no crescimento das vendas em $4,7 \%$, comercializados para o mercado externo.

Com base na abertura dos mercados e na inserção do mercado oriental, a tomada de decisão tornou-se cada vez mais presente no cotidiano das indústrias calçadistas brasileiras, em virtude da concorrência gerada e o baixo custo apresentado pelos produtos orientais. Neste cenário, as indústrias calçadistas do Vale do Rio dos Sinos sentiram de forma diferenciada os impactos desse novo ambiente competitivo, e passaram a adotar novas estratégias tecnológicas e de reestruturação. O principal objetivo era a redução dos custos de produção, para manter a competitividade no preço do produto.

A Schuler Calçados é uma empresa que surgiu em virtude do empenho e visão empreendedora do proprietário Davi Schuler. Depois de dezoito anos atuando no mercado internacional, o empresário começou a sentir o desafio de continuar exportando, pois estava se tornando impossível competir com os calçados chineses e asiáticos.

Conforme a Associação Brasileira das Indústrias de Calçados (ABICALÇADOS), as empresas calçadistas brasileiras enfrentaram redução em seus volumes de exportação (Tabela I), em função do acirramento da concorrência provocada pelos calçados orientais. Davi sentiu-se pressionado, pois a concorrência dispunha de calçados de qualidade similar e preço 
inferior. Estes fatos levaram o empresário a buscar novas estratégias para manter a sobrevivência de sua empresa. Entretanto, ele poderia optar por: i) sair do mercado internacional; ii) deslocar a empresa para outras regiões do Brasil em busca da redução dos custos de produção, e assim manter a competitividade no preço do produto; iii) adotar novas estratégias de produção, desenvolver um produto inovador, voltado às exigências dos consumidores brasileiros, e competir no mercado interno. Porém, diante destas possíveis opções para superar o desafio, Davi não tinha certeza de qual decisão deveria tomar.

Tabela 1 Histórico das exportações Brasileiras de calçados do ano de 1990 a 2002

\begin{tabular}{|llllll|}
\hline Ano & US\$ (milhöes) & $\%$ & Pares & $\%$ & PM \\
\hline 1990 & 1.107 & - & 143 & - & 7,74 \\
\hline 1991 & 1.177 & $6,3 \%$ & 133 & $6,9 \%$ & 8,85 \\
\hline 1992 & 1.409 & $19,7 \%$ & 158 & $18,9 \%$ & 8,91 \\
\hline 1993 & 1.846 & $31,0 \%$ & 201 & $27,4 \%$ & 9,16 \\
\hline 1994 & 1.537 & $-16,7 \%$ & 171 & $-15,0 \%$ & 8,97 \\
\hline 1995 & 1.414 & $-8,0 \%$ & 138 & $-19,4 \%$ & 10,25 \\
\hline 1996 & 1.567 & $10,9 \%$ & 143 & $3,4 \%$ & 10,98 \\
\hline 1997 & 1.523 & $-2,8 \%$ & 142 & $-0,1 \%$ & 10,69 \\
\hline 1998 & 1.330 & $-12,6 \%$ & 131 & $-8,0 \%$ & 10,16 \\
\hline 1999 & 1.278 & $-4,0 \%$ & 137 & $4,7 \%$ & 9,32 \\
\hline 2000 & 1.547 & $21,1 \%$ & 163 & $18,5 \%$ & 9,52 \\
\hline 2001 & 1.617 & $4,5 \%$ & 171 & $5,4 \%$ & 9,44 \\
\hline 2002 & 1.451 & $-10,3 \%$ & 164 & $-4,2 \%$ & 8,84 \\
\hline
\end{tabular}

Fonte: ABICALÇADOS (2009). 


\section{A SCHULER CALÇADOS}

Davi, desde muito jovem trabalhou no setor calçadista do Vale do Rio dos Sinos. A renda da família era pequena, o salário que o jovem recebia era utilizado para auxiliar o pai no pagamento das despesas da casa. Seu primeiro emprego foi aos 17 anos de idade, como aprendiz em um ateliê de calçados. Atuou neste mesmo ateliê como auxiliar de produção durante os dois anos seguintes (I977/I978).

Naquela época, tudo era difícil: jovens e sem experiência os trabalhadores eram pouco remunerados. No entanto, Davi sentia-se útil, pois mesmo com o baixo salário de aprendiz, conseguia contribuir para a renda familiar. Joaquim, seu pai, ficava comovido, pois o filho tão jovem dedicava-se ao trabalho e aos estudos e não dispunha de tempo para se divertir com os amigos de infância do bairro pobre em que residia.

Passaram-se dois anos, Davi foi promovido para trabalhar no setor de colagem do ateliê de calçados. Sempre mostrou interesse em um trabalho de qualidade, e aos 23 anos de idade já era o chefe de produção do ateliê em que iniciou como aprendiz.

Com muito esforço, o jovem conseguiu conciliar o trabalho e os estudos; sua dedicação fez com que concluísse o curso de Administração de Empresas com Ênfase em Comércio Exterior. A inteligência de Davi era ressaltada por todos os professores da Universidade, visto que no dia da formatura recebeu seu diploma de bacharel em Administração, com láurea acadêmica pelo elevado nível de aproveitamento durante o curso

Com visão empreendedora e certa economia em dinheiro, que acumulou com o trabalho, em abril de 1982, Davi tomou a iniciativa de montar uma pequena empresa. Necessitava de espaço adequado e mão de obra qualificada para a industrialização dos calçados. Contou com a ajuda de seu pai, alugou um pavilhão, contratou dois profissionais especializados, sendo um estilista-designer e um estilista-projetista, e vinte trabalhadores para o setor de produção. Assim, aconteceu a concretização do sonho de Davi, que era montar uma empresa e poder dedicar-se a ela, a qual recebeu o nome de Schuler Calçados. 
O Vale do Rio dos Sinos, na década de 1980, era uma região considerada como grande cluster do calçado, tendo-se em vista a disponibilidade de mão de obra qualificada; as concentrações geográficas de indústrias e afins; a presença de serviços de apoio tecnológico; e a existência de associações patronais. Davi percebeu que montar uma empresa para atuar no ramo de calçados nessa época era um ótimo negócio.

E assim sucedeu durante a década de 1990. A empresa cresceu rapidamente, voltando-se especialmente para o mercado externo no desenvolvimento de calçados com elevados padrões de qualidade. Em virtude da alta demanda, em 1993, a empresa foi deslocada para um novo prédio, e foram admitidos mais 8I trabalhadores para o setor de produção.

Em 1994, o cenário internacional de calçados começou a apresentar os primeiros indícios de mudança. $\mathrm{O}$ avanço da globalização e o surgimento da internacionalização de mercados fizeram as empresas brasileiras se atualizarem rapidamente, para fazer frente a essas novas situações competitivas. Segundo o Banco Nacional do Desenvolvimento Social (BNDES), embora tanto as exportações quanto as importações brasileiras de calçados tenham sido menores em 1997 do que em 1996, e o saldo tenha caído cerca de $8,5 \%$, este ainda continuava superior a US\$ I bilhão. Nessa mesma época, o Rio Grande do Sul apresentava grande representatividade no percentual de exportações de calçados de couro no Brasil (Tabela 2).

Tabela 2 Exportações de calçados por estados de origem de 1996 a 2001

\begin{tabular}{|c|c|c|c|c|c|c|}
\hline \multicolumn{7}{|l|}{ US\$̦/Milhões } \\
\hline Estado & 1996 & 1997 & 1998 & 1999 & 2000 & 2001 \\
\hline Ceará & 10,1 & 35,1 & 65,2 & 71,3 & 81,1 & 106,4 \\
\hline Paraíba & 3,7 & 3,9 & 9,8 & 16,3 & 17,0 & 26,6 \\
\hline Bahia & 0,00 & 0,00 & 0,1 & 1,7 & 4,9 & 8,9 \\
\hline Minas Gerais & 3,8 & 3,8 & 3,2 & 3,4 & 5,6 & 11,6 \\
\hline São Paulo & 149,2 & 127,2 & 98,7 & 90,2 & 135,4 & 133,0 \\
\hline Santa Catarina & 9,7 & 9,3 & 5,4 & 6,0 & 6,4 & 6,7 \\
\hline Rio Grande do Sul & $1.388,9$ & $1.341,6$ & $1.144,0$ & $1.084,7$ & $1.292,3$ & $1.316,7$ \\
\hline Brasil & $1.567,2$ & $1.522,9$ & $1.330,5$ & $1.277,8$ & 1546,7 & 1615,3 \\
\hline
\end{tabular}

Fonte: Resende e Perez (2004). 


\section{CONHECENDO A SCHULER CALÇADOS}

Anos se passaram. A Schuler Calçados em 20or contava, ainda, com um grande número de colaboradores, atuando preferencialmente no mercado externo, chegando a exportar para países americanos e europeus cerca de 90\% de sua produção anual, encontrando-se, dessa forma, pouco presente no mercado interno e em redes de lojas do Brasil (Tabela 3). O número de colaboradores no final do segundo semestre totalizava 392 empregos diretos, sendo a mão de obra utilizada, característica do setor calçadista. A empresa apresenta em seu organograma cargos distintos, mostrados na Figura I.

Tabela 3 Percentual de vendas entre 1994 e 2001

\begin{tabular}{|lll|}
\hline Ano & \% Mercado Interno & \% Exportações \\
\hline 1994 & 22 & 78 \\
\hline 1995 & 21 & 79 \\
\hline 1996 & 21 & 79 \\
\hline 1997 & 20 & 80 \\
\hline 1998 & 18 & 82 \\
\hline 1999 & 18 & 82 \\
\hline 2000 & 15 & 85 \\
\hline 2001 & 10 & 90 \\
\hline
\end{tabular}

Fonte: Schuler Calçados

Figura 1 Organograma da Schuler Calçados

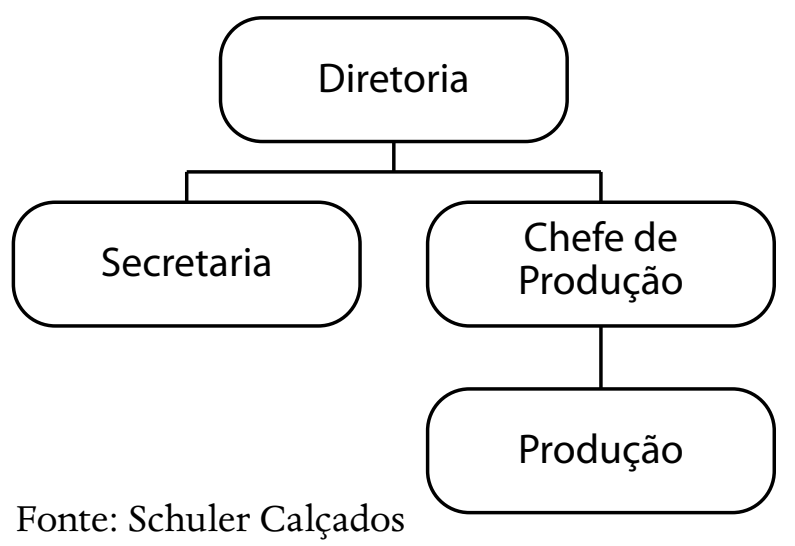


A empresa operava em um grande prédio, desenvolvendo todo o processo de produção, desde os setores de corte, costura, montagem e acabamento. Seu complexo industrial encontrava-se dividido em uma estrutura composta de escritórios, almoxarifado, sala médica, refeitório e estacionamento. A linha de produtos da empresa, sapatos de couro femininos, destinava-se preferencialmente para a exportação, sendo pequena a atuação no mercado interno.

\section{O CENÁRIO MUDOU}

Em meados de 2002, o diretor Davi, percebe que, para a sobrevivência e competitividade da empresa, precisa tomar uma decisão, pois a empresa encontra-se em deficit financeiro. Em uma fria noite de inverno, quando conduzia o carro para casa, ele fez um comentário com sua esposa Janete. "A atuação no mercado internacional está causando um sério impacto negativo nos resultados da empresa. Qual será a melhor estratégia a ser tomada diante de uma situação como esta?"

A gestão financeira da empresa, em 200I, está explícita no Balanço Financeiro dos Recursos Recebidos e os Recursos Aplicados correspondentes, transitados por Caixa e Bancos, conforme a Tabela 4.

O setor calçadista é caracterizado pela existência de indústrias com diferentes níveis de capacitação e eficiência de mercado, grande diversidade de segmentos, intensidade na utilização da mão de obra (principal fator de competitividade desse segmento industrial), relativa difusão tecnológica do processo produtivo e alta pulverização em nível mundial. O ambiente competitivo de mercado exige velocidade e altos índices de eficiência e de eficácia, levando as indústrias calçadistas a enxugarem todos os processos que não agregam valor e a redesenhar os remanescentes. As estratégias organizacionais são fundamentais para a criação de vantagens competitivas sustentáveis, bem como para o alcance do desempenho esperado.

A entrada da China e da Ásia no mercado internacional de calçados acabou por alterar as condições de prosperidade da região. Pressionados por produtos de qualidade similar e preços inferiores, as empresas locais, 
atuantes nos mercados de menor valor agregado, não souberam quais estratégias tomarem perante as novas regras vigentes.

Tabela 4 Balanço financeiro da Schuler Calçados em 2001

\begin{tabular}{|ll|}
\hline Balanço Financeiro - 2001 (em R\$) & Valor \\
\hline Discriminação & $720.964,47$ \\
\hline Saldo do exercício anterior & $93.556 .793,09$ \\
\hline Recursos recebidos no exercício & $94.277 .757,56$ \\
\hline Total dos recursos disponíveis & $94.287 .535,35$ \\
\hline Recursos despendidos no exercício & $-9.777,79$ \\
\hline Disponibilidade final em 31/12/2001 & \\
\hline
\end{tabular}

Fonte: Schuler Calçados

\section{SURGEM ALGUMAS POSSIBILIDADES}

Ciente do problema, o empresário necessitava tomar uma ação o mais breve possível. Após reunir-se com o administrador da empresa, percebeu que a saída do mercado internacional afetaria a produção da empresa, a qual sofreria uma redução considerável. Esse fato também ocasionaria a demissão de um grande número de colaboradores.

No caso de deslocar a empresa para outras regiões do Brasil, como por exemplo, o Nordeste do País, utilizando estratégia de redução dos custos de produção, obtidos por meio de baixo custo de mão de obra e incentivos fiscais, para manter a competitividade no preço do produto, corria-se o risco de essas regiões já estarem saturadas, em virtude de muitas empresas terem migrado com o mesmo propósito. Para as empresas do setor calçadista, era clara a tendência de relocalização de unidades produtivas para a região Nordeste do País, especialmente para os Estados do Ceará e Bahia, visto que entre os anos de 1990 e 1999 houve aumento de $200 \%$ no total de empregos gerados pela indústria calçadista no Nordeste, particularmente no Ceará.

As empresas que estabeleceram unidades industriais na região Nordeste do país buscavam menores custos de produção. Essa redução de custos se 
dava em várias frentes. A primeira delas referia-se aos custos do trabalho, provenientes do pagamento de salários aos trabalhadores. Na região Nordeste, esses custos eram significativamente menores do que os custos verificados nas regiões tradicionais. Considerando apenas o Estado do Ceará, verificava-se que $88 \%$ dos trabalhadores da indústria calçadista tinham renda média inferior a dois salários mínimos, enquanto nos Estados de São Paulo e Rio Grande do Sul esse porcentual passava para $29 \%$ e $34 \%$, respectivamente. A disparidade de salários entre as regiões brasileiras está evidenciada na Tabela 5. Esses dados também revelam que não era somente o nível de salários que explica as estratégias de relocalização. Estados como o Piauí apresentavam salários ainda mais baixos, porém, não eram capazes de atrair as empresas calçadistas. Como será visto a seguir, os incentivos fiscais tiveram papel central nesse processo de relocalização.

Em virtude da transferência de capitais para o Nordeste, o setor calçadista enfrentou dificuldades para se expandir com mais vigor e competitivamente. Apesar dos incentivos, em relação aos investimentos dever-se-ia ter em conta que existiam lacunas na cadeia produtiva regional, estas ligadas ao fornecimento de alguns insumos, que aumentavam os custos de transporte, diminuindo a competitividade, principalmente das empresas menores. No entanto, insuficiências estruturais, tais como: parque de máquinas antigo e defasado tecnologicamente, para fazer parte a tal empreendimento poderia abalar a migração da empresa; a questão do tempo também poderia ser um fator negativo, caso fosse necessário treinamento para dispor de mão de obra qualificada.

Outra possibilidade vista por Davi seria competir por meio de um produto inovador. Para tanto, seria necessário investigar o ambiente de mercado a fim de conhecer as tendências e antecipar as oportunidades, e, com base nas necessidades dos consumidores, focar um segmento, desenvolvendo um novo produto para atuar exclusivamente no mercado interno. O empresário também poderia utilizar uma estratégia de distribuição por meio de comunicação rápida entre as vendas e com flexibilidade em relação à entrega dos produtos aos clientes. 
Tabela 5 Salários pagos na indústria calçadista brasileira

\begin{tabular}{|lll|}
\hline Estados & 1986 & 1998 \\
\hline Piauí & 0,43 & 0,49 \\
\hline Ceará & 0,60 & 0,76 \\
\hline Paraíba & 0,65 & 0,81 \\
\hline Pernambuco & 0,95 & 1,22 \\
\hline Bahia & 0,54 & 0,63 \\
\hline Minas Gerais & 0,73 & 0,71 \\
\hline Rio de Janeiro & 0,80 & 1,15 \\
\hline São Paulo & 1,09 & 1,13 \\
\hline Paraná & 0,68 & 0,75 \\
\hline Santa Catarina & 0,67 & 0,73 \\
\hline Rio Grande do Sul & 1,05 & 1,08 \\
\hline Goiás & 0,52 & 0,55 \\
\hline
\end{tabular}

Fonte: Azevedo e Toneto (2001).

Nota: Estados selecionados (média brasileira $=1$ )

Todavia, essa inovação poderia levar algum tempo, e Davi tinha receio que não suportaria financeiramente a espera, já que sua empresa nesse período estava com deficit financeiro. Todas as ações propostas ocasionavam dúvidas, pois o empresário sabia que o Vale do Rio dos Sinos tinha assistido atônito a uma série de falência de empresas do ramo calçadista. 


\section{NOTAS DE ENSINO}

\section{UTILIZAÇÃO RECOMENDADA}

O caso de ensino foi elaborado para aplicação em cursos de graduação em administração nas disciplinas de teorias organizacionais, diretrizes e planejamento empresarial, administração de novos negócios, inovação e empreendedorismo, estratégia de inserção internacional e inteligência competitiva, gestão estratégica de pessoas, comportamento organizacional, estratégia em comércio internacional e empreendedorismo internacional.

\section{OBJETIVOS DE APRENDIZAGEM}

Com a análise do caso da empresa Schuler Calçados será possível abordar e refletir sobre vários temas de aprendizagem.

a) Decisões e ações associadas ao empreendedorismo e à inovação no contexto da Indústria Calçadista do Vale do Rio dos Sinos;

b) A dificuldade das organizações perante as mudanças, no cenário externo, tendo que se adaptar a elas, bem como o empreendedorismo internacional;

c) A globalização obriga as empresas a estar cada vez mais perto do cliente, analisar o consumidor, envolver-se com a cultura e o costume, com os problemas, com fatores de mercado (econômicos, competências e tendências);

d) Se as adversidades macroeconômicas, basicamente câmbio, excesso de tributação e juros muito altos fossem alteradas, as empresas brasileiras não precisariam atuar fora do seu ambiente;

e) A adoção de estratégias como introdução de novos produtos surgiria em resposta ao novo ambiente competitivo, podendo reduzir custos de produção e ganhar velocidade de resposta às modificações da demanda;

f) A gestão de pessoas, em ambientes de mudança, exige dos líderes da organização uma postura de incentivadora, inovadora e de capacidade adaptativa com relação ao novo contexto. 


\section{SUGESTÕES DE QUESTIONAMENTOS PARA DISCUSSÃO EM SALA DE} AULA

I) O cenário atual cada vez mais competitivo está em constante mudança. Qual o perfil do gestor de uma organização para que venham a ser possíveis a percepção dessas mudanças e a rápida adaptação a elas?

2) Com o avanço da globalização e o surgimento da internacionalização de mercados, as organizações perceberam o turbilhão competitivo no qual estavam envolvidas; nesse contexto, é flagrante a importância da tomada de decisão? Por quê?

3) No caso de ensino descrito, nos níveis de estratégias definidas por Paiva, Carvalho e Fensterseifer (2004), em qual deles Davi poderia ter maior sucesso?

4) Baseadas nas cinco forças competitivas, citadas por Porter (I986, 1989), qual delas está atuando nesta situação?

5) Schumpeter (1982) menciona diferentes formas de inovação. Qual delas poderia ter maior êxito perante o caso descrito?

6) Caso você fosse o personagem Davi, referido no caso, perante a situação descrita, que ação estratégica você tomaria e por quê? 


\section{POSSIBILIDADES PARA ANÁLISE DO CASO}

\section{MUDANÇAS NO CENÁRIO}

Uma das questões a serem levantadas sobre este caso refere-se à capacidade necessária do gestor de perceber situações de oportunidades e de conflitos, com base na análise do cenário e do posicionamento da empresa neste contexto. O administrador deve perceber que o bom desempenho da empresa está no fato de não se ter ideias imutáveis sobre as fontes de vantagem competitiva da organização, além disso, estar em constante atenção com fatos externos e internos no cenário de sua organização, para captar as possíveis alterações que venham a ocorrer.

As mudanças na organização são forçadas, em parte, por novas tecnologias, e, em parte, pelas exigências de uma sociedade baseada no conhecimento, na qual o aprendizado precisa se tornar um processo vitalício para os trabalhadores do conhecimento, e, em parte, pela teoria de como aprender, aprendendo. Na verdade, esses fatores estão interligados; a separação só ocorre para fins de uma melhor compreensão (DRUCKER, 1986).

Algumas forças agem no processo de mudança: a tecnológica, a formação de áreas de livre comércio e dos blocos econômicos, a crescente interligação e interdependência dos mercados físicos e financeiros. A presença de concorrentes estrangeiros, a ausência de barreiras de entrada, o aumento da concorrência no setor privado tem impulsionado mudanças acentuadas nos cenários competitivos das empresas, induzindo ao aumento da competitividade e à modernização empresarial. As inovações tecnológicas e as transformações sociais dominam a sociedade atual, mudam profundamente a produção de bens e a vida das pessoas (моттA, 1998).

As pressões para a mudança em busca de maior competitividade têm diferentes origens. Apesar de muitas organizações terem consciência de que existem muitos obstáculos, durante a implantação de uma mudança estratégica, poucas ações concretas são levadas a efeito neste sentido. É raro que as empresas considerem os riscos causados pela vulnerabilidade dos seus ativos humanos. As dificuldades na implantação de melhorias estão 
muito relacionadas com a ausência de treinamento aos empregados, clima motivacional desfavorável, deficiências na qualidade de vida no trabalho e dificuldades com novas tecnologias (FLEURY; FLEURY, I995)

Neste cenário, o mercado globalizado, que é caracterizado pela ausência de fronteiras, enfoca novas diretrizes para a atuação empresarial, tais como criação de valor, flexibilidade e aprendizagem, tecnologia da informação e formação de redes baseadas no estreitamento dos relacionamentos intra e interorganizacionais. Assim, as organizações necessitam desenvolver um entendimento mais sofisticado das diferenças culturais, que marcam suas interações no ambiente global.

Para Prahalad e Hamel (1998), os gerentes das unidades estratégicas falharam em observar a ênfase que os concorrentes asiáticos deram na liderança em produtos essenciais ou em entender a conexão crítica entre liderança mundial em fabricação e a capacidade de sustentar um ritmo de desenvolvimento em competências essenciais. $\mathrm{O}$ autor também cita que a capacidade de se adaptar rapidamente às oportunidades é a fonte de vantagem das organizações. Quanto mais rápido a empresa compreender o novo cenário e posicionar-se nele, maior será a possibilidade de obtenção de sucesso. Assim, evidencia-se a importância de uma visão de longo prazo por parte das organizações para que, em função desta visão, os objetivos possam ser claramente estabelecidos e se obtenham melhores condições de evitar eventuais conflitos entre as atividades diárias e os resultados futuros desejados. Sem essa visão, a pressão por resultados imediatos pode comprometer o posicionamento de mercado e a competitividade da organização no futuro.

Neste cenário, fica implícito a importância de acompanhar atentamente as mudanças do ambiente competitivo, os comportamentos dos concorrentes e as necessidades e desejos de clientes e consumidores, bem como os interesses dos diferentes stakeholders. Quanto mais objetiva for a análise da situação atual da organização e mais consistente a definição de seu posicionamento desejado, melhores serão as condições para que a organização estabeleça vantagens competitivas sustentáveis. Para tanto, sejam quais forem os caminhos escolhidos em função de contingências e alterações transitórias 
no ambiente competitivo, o caminho mais correto para assegurar uma futura lucratividade sustentável é adotar ações estratégicas, que fortaleçam a competitividade e o posicionamento do negócio. Sempre que uma empresa abdicar de um posicionamento claro em nome de resultados imediatos, sua rentabilidade futura será colocada em risco.

\section{AÇÃO ESTRATÉGICA}

Outro ponto a ser levantado é qual estratégia Davi teria que tomar perante o desafio? Conforme Collis e Montgomery (200I), o campo de estratégia foi concebido inicialmente por Kenneth Andrews em 1971, que define estratégia como a compatibilização entre o que a empresa é capaz de fazer (pontos fortes e fracos da organização) no contexto do universo do que poderia fazer (oportunidades e ameaças do ambiente externo). A estratégia trata do conjunto de planos e políticas pelos quais uma companhia objetiva ganhar vantagem competitiva sobre seus competidores e inclui planos para a produção e venda de produtos para um conjunto particular de consumidores. Neste contexto, Slack, Chambers e Johnston (2002) definem estratégia como o padrão global de decisões e ações, que posicionem a organização em seu ambiente e tenham o objetivo de fazê-la atingir seus objetivos para longo prazo.

Para Paiva, Carvalho e Fensterseifer (2004), a definição da estratégia da empresa pode acontecer em três níveis: estratégia da corporação (do grupo empresarial); estratégia de negócios (relaciona-se com a obtenção e manutenção da vantagem competitiva); estratégia funcional (relacionada com diversas áreas da estratégia de negócios, como manufatura, marketing, finanças, entre outras). A inter-relação entre esses níveis será fundamental para a manutenção de uma estratégia bem-sucedida.

Segundo Porter (1986, 1989), a formulação da estratégica está baseada em cinco forças, que determinam a dinâmica da competição em uma indústria: poder de barganha dos clientes; poder de barganha dos fornecedores; setor competindo por uma posição entre os concorrentes existentes; ameaça de produtos ou serviços substitutos; ameaça de entrantes potenciais. Para enfrentar essas cinco forças competitivas de cada segmento industrial 
a empresa pode utilizar três abordagens diferentes para a estratégia de negócios; são elas:

I) Liderança em custos: considera a necessidade de ganhar em escala, desde a compra da matéria prima e a produção até a negociação com os clientes. Pode requerer investimentos pesados de capital em equipamentos atualizados, fixação de preços agressiva e prejuízos iniciais para consolidar a parcela de mercado. Pode ser vista também como a abordagem que orientou os princípios da produção em massa no início do século xx;

2) Diferenciação: buscam-se as características únicas e exclusivas no produto ou serviço oferecido pela empresa, criando, assim, algo que seja reconhecido como diferencial no âmbito competitivo no qual a empresa está inserida. Pressupõe a qualidade ou outra forma de diferenciação no produto ou serviço oferecido;

3) Enfoque: atuar em determinado segmento de mercado. A estratégia toma por base que, com a focalização no segmento específico, a empresa poderá competir tanto em termos de custo como em termos de diferenciação.

Uma vez analisadas as forças que afetam a competição em um setor e suas causas, o estrategista pode identificar os vigores e as fraquezas de sua empresa. E, com base nisso, tomar a decisão estratégica mais acertada.

Conforme Oliveira (200I), a implantação de uma estratégia empresarial, pode vir a ser um novo produto ou serviço, cliente ou tecnologia que exige alterações internas na empresa. Várias informações estratégicas devem ser analisadas para ter-se um bom desempenho empresarial, são elas: clientes, concorrentes, demografia, ecologia, economia, fornecedor, governamental/ política, legal, sindical, social e tecnológica. Torna-se de suma importância para uma organização, ficar atenta ao surgimento de oportunidades e desenvolver a capacidade de colocar no mercado o melhor produto possível para aproveitá-la, beneficiando-se depois da aprendizagem decorrente do feedback dos consumidores para aprimorar esta solução. Assim, enquanto os concorrentes ainda correm para aproveitar o restante da oportunidade, as organizações mais eficientes já estão vislumbrando a próxima janela de oportunidades. 


\section{EMPREENDEDORISMO E INOVAÇÃO}

Decisões e ações associadas ao empreendedorismo e inovação poderiam ser tomadas pelo protagonista, a inovação pode ocorrer em produtos, processos, forma de organização e gerenciamento do processo.

Schumpeter (1982) por meio da obra Teoria do Desenvolvimento Econômico desenvolveu a abordagem conceitual da inovação, dando a ela um lugar de destaque na teoria do desenvolvimento econômico. Para Schumpeter o desenvolvimento econômico, nas economias capitalistas, é conduzido pelo impacto das inovações tecnológicas, as quais ocorrem por meio de um processo dinâmico, denominado de destruição criadora, no qual as novas tecnologias substituem as antigas, contrapondo a ideia do equilíbrio geral da economia, tal como descrito na teoria neoclássica. Neste cenário, as inovações tecnológicas introduzidas pelos empresários inovadores foi o principal estímulo para o início de um novo ciclo econômico (SCHUMPETER, 1982).

A inovação se trata da capacidade para produzir novas máquinas ou produtos, novas soluções organizacionais no processo de produção e no mercado, a palavra inovação está atrelada a mudança. A Organização para Cooperação e Desenvolvimento Econômico - OCDE (198I) traz que inovação é a transformação de uma ideia em um produto novo ou melhorado, vendível, ou em um processo produtivo, comercial ou industrial, ou ainda em um novo método de serviço social. Assim, a inovação abrange todas as medidas técnicas, científicas, comerciais e financeiras necessárias para garantir o êxito do desenvolvimento dos processos, produtos ou serviços.

Para Dornelas (2003) as características comuns aos empreendedores são apontadas por serem: visionários, sabem tomar decisões, fazem a diferença, sabem explorar ao máximo as oportunidades, determinados e dinâmicos, otimistas e apaixonados pelo que fazem, dedicados, independentes e constroem seu próprio destino, líderes e formadores de equipes, bem relacionados, organizados, excelentes planejadores, possuem conhecimento, assumem riscos calculados e criam valor para a sociedade. Neste contexto, o Global Entrepreneurship Monitor (GEM, 2000) define empreendedorismo como qualquer tentativa de criação de um novo negócio ou novo 
empreendimento, como, por exemplo, a atividade autônoma, uma nova empresa ou a expansão de um empreendimento existente, por um indivíduo, grupos de indivíduos ou por empresas já estabelecidas.

Hisrich e Peters (2004) ressaltam que o empreendedorismo é o processo dinâmico de criar mais riqueza. A riqueza é criada por indivíduos que assumem os principais riscos em termos de patrimônio, tempo e/ou comprometimento com a carreira ou que provêm valor para algum produto ou serviço. O produto ou serviço pode ou não ser novo ou único, mas o valor, deve de algum modo, ser infundido pelo empreendedor ao receber e localizar as habilidades e os recursos necessários.

De acordo com Timmons e Spinelli (2007), existem seis competências essenciais ao comportamento empreendedor: compromisso e determinação; liderança; busca por oportunidades; tolerância ao risco, ambiguidade e incerteza; criatividade, independência e adaptabilidade; e motivação para superação. Além desses, existem também atributos desejáveis que são: inteligência; capacidade para inspirar; valores; energia, saúde e estabilidade emocional; e criatividade e inovação.

Para Drucker (I986), a inovação e o espírito empreendedor são necessários na sociedade tanto quanto na economia; na instituição de serviço público tanto quanto em empresas privadas. A inovação e o empreendimento não constituem algo radical, o empreendimento é pragmático e não dogmático, e se propõe manter qualquer sociedade, economia, indústria, serviços públicos, ou empresas, flexíveis e auto-renovadoras. A inovação pode ser definida como a ferramenta dos empreendedores, o meio pelo qual exploram as mudanças como uma oportunidade para oferecer um novo serviço ou produto. Neste contexto, Dosi (1988), afirma que inovação diz respeito à busca, descoberta, experimentação, desenvolvimento, imitação e adoção de novos produtos, novos processos de produção ou novas formas organizacionais.

Dolabela (1999) defende o empreendedorismo como forma de ser. Diz o autor, que empreendedor é alguém que sonha e busca transformar um sonho em realidade, e, uma vez definidos os seus sonhos, ele os projeta com um horizonte futuro. Independente de onde provêm as fontes de 
informação, sempre a figura do empreendedor será relacionada a alguém inovador, inquieto, criativo, planejador e com os olhos e pensamentos voltados para o futuro.

Segundo Sbragia et al. (2006), inovação é um processo sistêmico envolvendo inúmeros atores que atuam, conforme lógicas e prioridades distintas, e se realizam somente em um ambiente estimulante e catalisador de competências e iniciativas de cada um. $\mathrm{O}$ atual quadro econômico, marcado pela alta competitividade, qualidade dos produtos e concorrência acirrada, cada vez mais se está dependente da capacidade de inovação tecnológica da empresa, introduzindo novos produtos no mercado, com menor preço, qualidade superior e velocidade melhor que a concorrência. Porém, inovação requer recursos; inovar é apostar em ideias que, potencialmente, podem contribuir para os objetivos da organização. Essa potencialidade implica riscos. Nesse sentido, o protagonista teria que analisar a viabilidade deste processo, pois inovação requer incentivos e, principalmente, recursos. E, com base nisso, tomar a decisão de implantar ou não este processo.

Schumpeter (1982) menciona cinco formas de inovação: introdução de um novo bem; introdução de um novo método de produção; abertura de um novo mercado; conquista de uma nova fonte de matéria-prima; aparecimento de uma nova estrutura de organização em um setor. Contudo, atualmente o Manual de Oslo (2005) classifica as inovações em quatro dimensões, sendo elas:

I) Inovação de Produto: consiste na introdução de um produto (bem ou serviço) novo ou significativamente melhorado no que diz respeito as suas características ou usos previstos dos produtos previamente produzidos pela empresa;

2) Inovação de Processo: processo novo ou substancialmente aprimorado, envolve a introdução de tecnologia de produção nova ou significativamente aperfeiçoada, de métodos para oferta de serviços ou para manuseio e entrega de produtos novos ou substancialmente aprimorados, como também de equipamentos novos ou significativamente aperfeiçoados em atividades de suporte à produção; 
3) Inovação em Marketing: consiste na implantação de um novo método de marketing com mudanças significativas na concepção do produto ou em sua embalagem, no posicionamento do produto, em sua promoção ou na fixação de preços. Inovações de marketing são voltadas para melhor atender as necessidades dos consumidores, abrindo novos mercados, ou reposicionando o produto de uma empresa no mercado, com o objetivo de aumentar as vendas.

4) Inovação Organizacional: a inovação organizacional acontece por meio da implantação de um novo método organizacional nas práticas de negócio da empresa, na organização do seu local de trabalho ou em suas relações externas desde que não tenha sido utilizada anteriormente pela empresa e que seja resultado de decisões estratégicas.

Considera-se que a possibilidade de inovar em produtos/serviços, em processos, em marketing e na gestão da organização está ligada diretamente às características que compõem o perfil do empreendedor e dos funcionários da empresa (MANUAL DE OSLO, 2005; DORION et al., 20IO), pois, para haver inovação é necessário um ambiente na organização que suporte os diferentes processos inovadores. Analisando estas diferentes formas de inovação, o empresário poderia identificar a que melhor se enquadra dentro da sua empresa. E, dessa maneira, tomar a decisão mais adequada.

Outra forma de inovar é repensar os mercados em que a empresa atua, ampliandooraiode atuação, comoocorrenosprocessosdeinternacionalização da empresa, por meio do empreendedorismo internacional. Para Hisrich e Peters (2002), o empreendedorismo internacional ocorre quando as atividades empresariais, exercidas por um empreendedor, vão além das fronteiras nacionais, por meio de novos empreendimentos em outros Países, considerando a dificuldade de competividade global, os fatores cultuais, econômicos, políticos e legais, o que torna a decisão mais complexa em relação ao empreendedorismo doméstico. 


\section{OBTENÇÃO DOS DADOS}

Os dados foram coletados com base em entrevista realizada com o personagem principal do caso. Posteriormente à coleta dos dados, foram feitas tanto a transcrição como a interpretação da entrevista, onde se buscou, juntamente com a história real, a colocação de alguns elementos fictícios para chamar a atenção do leitor ao conflito existente e, também, para que a história tomasse um cunho acadêmico. Sendo assim, a história verdadeira do personagem foi alterada, bem como o nome da empresa e do proprietário são fictícios para preservar o caso real. 


\section{REFERÊNCIAS}

ABICALÇADOS - Associação Brasileira das Indústrias de Calçados. Disponível em: $<$ http://www.abicalcados.com.br/documentos/resenha_estatistica/Historico $\% 20$ das\%20Exportacoes\%202009.pdf $>$. Acesso em: 12/02/2009.

AZEVEDO, P. F.; TONETO J. R. Determinantes da relocalização do emprego formal no Brasil: evidências a partir de setores selecionados. Pesquisa e Planejamento Econômico, IPEA, 2001.

BNDS - BANCO NACIONAL DO DESENVOLVIMENTO SOCIAL. Informe Setorial $n^{\circ}$ 13. Disponível em: <http://www.bndes.gov.br/conhecimento/setorial/gs2_13.pdf >. Acesso em: 12/02/2009.

COLLIS, D. J.; MONTGOMERY, C. A. Competindo com base em recursos: estratégia na década de 1990. Harvard Business Review. Estratégia corporativa. São Paulo: Campus, 2001.

DOLABELA, F. A Oficina do Empreendedor: a metodologia de ensino que ajuda a transformar conhecimento em riqueza. São Paulo: Cultura Editores Associados, 1999.

DORNELAS, J. C. A. Empreendedorismo corporativo: como ser empreendedor, inovar e se diferenciar em organizações já estabelecidas. Rio de Janeiro: Elsevier, 2003.

DORION, E.; CHALELA, L. R.; LAZZARI, F.; SEVERO, E. A.; GIULIANI, A. C. Profiles of entrepreneurship and innovation: debate on business incubators in Brazil. World Review of Entrepreneurship, Management and Sustainable Development, v. 6, n.1, p. 17-34, 2010.

DOSI, G. The nature of the innovative process. In: DOSI, G.; FREEMAN, C.; NELSON, R.; SILVERBERG, G.; SOETE, L. (Orgs.). Technical change and Economic Theory. London: Pinter Publishers, 1988.

DRUCKER, P. F. Inovação e espírito empreendedor (entrepreneurship): prática e princípios. São Paulo: Thomson Pioneira, 1986.

FENSTERSEIFER, J. E.; GOMES, J. A. Análise da cadeia produtiva do calçado de couro. In: FENSTERSEIFER, J. E. (Org.). O complexo calçadista em perspectiva: tecnologia e competitividade. Porto Alegre, 1995.

FLEURY, A.; FLEURY, M. T. L. Aprendizagem e Inovação Organizacional. São Paulo: Atlas, 1995.

GEM - GLOBAL ENTREPRENEURSHIP MONITOR. Empreendedorismo no Brasil 2000: Relatório Nacional. Curitiba: IBQP, 2001.

HISRICH, R. D.; PETERS, M. P. Entrepreneurship. 5.ed. McGraw-Hill, 2002.

MANUAL DE OSLO. Diretrizes para coleta e interpretação de dados sobre inovação. 3.ed. Paris: OCDE, 2005.

MOTTA, P. R. Transformação Organizacional. Rio de Janeiro: Qualitymark, 1998. 


\section{OCDE - ORGANIZAÇÃO PARA A COOPERAÇÃO E DESENVOLVIMENTO} ECONÔMICO. Manual de Frascati. Paris: 1981.

OLIVEIRA, D. P. R. Estratégia empresarial e vantagem competitiva: Como estabelecer implantar e avaliar. São Paulo: Atlas, 2001.

PAIVA, E. L., CARVALHO, M. C. J.; FENSTERSEIFER, J. E. Estratégias de produção e operações. Porto Alegre: Bookman, 2004.

PRAHALAD, C. K.; HAMEL, G. A. Competência essencial da corporação. In: MONTGOMERY, C. A.; PORTER, M. E. (Orgs.). Estratégia: a busca da vantagem competitiva. Rio de Janeiro: Campus, 1998.

PORTER, M. E. Estratégia competitiva: técnicas para análise de indústrias e da concorrência. Rio de Janeiro: Campos, 1986.

PORTER, M. E. Vantagem competitiva: criando e sustentando um desempenho superior. Rio de Janeiro: Campos, 1989.

RESENDE, J. V.; PEREZ, L. H. Exportações brasileiras de calçados, 1996 a 2003. Informações Econômicas, São Paulo, v. 34, n.11, 2004.

SCHUMPETER, J. A. A Teoria do desenvolvimento econômico. São Paulo: Abril, 1982. SBRAGIA, R.; STAL, E.; CAMPANÁRIO, M. A.; ANDREASSI, T. Inovação: como vencer esse desafio empresarial. São Paulo: Clio, 2006.

SLACK, N.; CHAMBERS, S.; JOHNSTON, R. Administração da Produção. São Paulo: Atlas, 2002.

TIMMONS, J. A.; SPINELLI, S. New venture creation: entrepreneurship for the 21st century. New York: McGraw-Hill; Irwin, 2007. 


\section{DADOS DOS AUTORES}

ELIANA ANDRÉA SEVERO^ elianasevero2@hotmail.com

\section{Mestre em Administração pela UCS}

Instituição de vinculação: Universidade de Caxias do Sul Caxias do Sul/RS - Brasil Áreas de interesse em pesquisa: Inovação e Sustentabilidade Ambiental.

${ }^{\star}$ Rua Francisco Getúlio Vargas, 1130 Universitário Caxias do Sul/RS 95070-560

\section{MARCIA RHOR DA CRUZ marciarohrcruz@gmail.com}

\section{Mestre em Administração pela UCS}

Instituição de vinculação: Universidade de Caxias do Sul Caxias do Sul/RS - Brasil Áreas de interesse em pesquisa: Inovação e Gestão da Produção.

PELAYO MUNHOZ OLEA pelayo.olea@gmail.com

Doutor em Administração e Direção de Empresas pela Politècnica de Catalunya, ETSEIB/UPC, Espanha

Instituição de vinculação: Universidade de Caxias do Sul Caxias do Sul/RS - Brasil Áreas de interesse em pesquisa: Inovação e Competividade.

ERIC DORION echdorion@gmail.com

Doutor em Administração pela Université de Sherbrooke, Canadá

Instituição de vinculação: Universidade de Caxias do Sul Caxias do Sul/RS - Brasil Áreas de interesse em pesquisa: Inovação e Competividade.

JULIO CESAR FERRO DE GUIMARÃES juliocfguimaraes@yahoo.com.br Mestre em Engenharia da Produção pela UFRGS

Instituição de vinculação: Universidade de Caxias do Sul Caxias do Sul/RS - Brasil Áreas de interesse em pesquisa: Inovação e Competividade. 